\title{
GENERIC USER MANUAL FOR MAINTENANCE OF MOUNTAIN BIKE BRAKES BASED ON AUGMENTED REALITY
}

\author{
Jorge Martín-Gutierrez* \\ Departamento Expresión Gráfica en Arquitectura e Ingeniería, Universidad de La Laguna, La Laguna, Spain \\ * Corresponding author (jmargu@ull.es)
}

\begin{abstract}
New smartphones generation provided with webcams, tactile screen and internet connection allow adaptation of new technologies and computer applications to this kind of devices. Augmented reality technology becomes widespread and more used each time by everyone. Augmented reality (AR) seeks creating virtual objects in user interface which superimpose over the physical environment. Equipment maintenance as well as training tasks are both excellent fields for developing augmented reality applications, in fact, several apps of Augmented Reality have been performed in very specific systems and complex (aircrafts, military equipment ...). In this paper our aim is making this technology approachable for applications and tasks quite common to everybody, so two prototypes have been developed : one smartphones-based mobile AR system and another video see-through based AR system which will guide the user step by step through installation of the V-brakes system, change of cartridge shoes and adjustment of tension cable. An easy interface based of several cards containing markers with codified sequences based in 3D models for performing maintenance, is fitted to the bike handlebars. Usability study results illustrate the feasibility of the prototype in both versions considering use of the smartphone for domestic and user tasks meanwhile virtual glasses are advised for more complex maintenance which may require use of both hands.
\end{abstract}

Keywords: Augmented Reality, Maintenance Tasks, Braking System

\section{INTRODUCTION}

Augmented reality technology has been applied in maintenance procedures at industrial environments turning out as an efficient technology applied to training and maintenance task of complex mechanical equipments requiring use of great deal of documents and manuals [1]. In closer surroundings, every device bought is provided with an instruction manual which may not be as clear as they should. Mostly, user opts for performing installation or setup in an intuitive way spending more time than necessary. General idea which this paper hopes to contribute is providing assistance to the user which has to perform assembly, setup, installation and maintenance of home appliances through augmented reality technology.

The AR system specified in this paper is dedicated to those situations and its aims are:
- Providing assistance to the mountain bike user in one of the most common maintenance tasks required by bikes: installation, check and tension adjustment of the braking system. It's an easy job but making it for the first few times can be difficult for the user. User must check periodically the bike brakes for being sure they are working properly avoiding unexpected frights. Brakes performance will be fine if they are in perfect conditions so braking system should undergo several checks.

- Being a friendly application for the user, making he feel comfortable using it so he may regard it as useful.

Augmented Reality (AR) consists in giving users all information needed for safe and efficient maintenance or installation procedures. This information, which we may call virtual information, is provided superimposing it over 
the real image captured with a camera and it's shown to the user through a screen. In our case two versions have been developed, one for being visualized through a smartphone screen and another visualized through a HMD connected to a PC. In both cases audio instructions are provided for being listened by the user. All virtual information are 3D objects which will be superimposed over the real ones so positions of each piece can be identified by the user before handling them.

\section{AR SYSTEMS AND INDUSTRIAL APPLICATIONS}

Since the late 90s, augmented reality has been a quite active investigation field in different domains such as manufacturing [2][3], medicine [4][5], education [6] among others. Although actually investigation is still an important pillar the needed conditions are in its favor for being introduced together with other technologies in consumer market applications (internet, portable devices...). Even when the original idea for use of AR in manufacturing, maintenance, repair and training in industrial environment dates back to the early 1990’s [7], it has not been generally implemented until now as a real product.

In less accessible fields like aerospace, applications have been developed for supporting maintenance staff while performing their tasks [8] [9] [10]. Schwald, introduces two AR systems for training \& assistance in maintenance of complex industrial equipment using an optical seethrough head mounted display [1] [12]. Unlike any other application fields in industrial environments, different kinds of AR systems may be developed according to performed tasks (mobile and non-mobile AR systems). One example of mobile AR system for the maintenance of power plants can be found in [13].

ARMAR project, has developed, designed, implemented and tested on users a beta version of an AR application for support of army mechanics during routine maintenance tasks inside an armored vehicle turret [14] [15].

Actually, mechanics from the army and manufacturers like Boeing use AR glasses when staff works on vehicles, glasses show repairs step by step, target necessary tools including textual instructions [11]. This kind of experience supports learning as well training of specific tasks.

Following bibliographic references, it could be figured out that use of AR technology in repair and maintenance fields is subject to complex systems although that's not the case because it's actually available to anyone. A few years ago, AR apps demanded specialized equipment which wasn't portable. Nowadays applications for laptops and smartphones merge digital information into the real world quick and easily. An example of AR application for maintaining photovoltaic solar installations equipment, in portable platform (Tablet PC) can be checked at [16].

Design of easy apps makes communication between people and computers more natural each time allowing those who are not used to computers can interact with the system.

\section{USER AR-MANUAL}

Work introduced here is development of an AR based application, as assistance in maintenance and adjustment of a standard mountain bike brakes system. Also, it focuses on making the AR system useful as training for all bicycle users aiming to replace the troublesome maintenance manuals and assembly instructions. Augmented manual called AR_V-Brakes manual consists of markers spotted by the camera of the used platform as 3D graphic information which will be superimposed upon the real scene. AR system is developed in two platforms: smartphone visualization and computer visualization through HMD. First of them has been developed for being accessible to everyone while the second is the most suitable platform for machines requiring more complex maintenance tasks or using both hands for performing them.

Augmented manual is presented in spiral binding so it can be leant over the mountain bike's handlebar. Each page has a marker that belongs in AR to every task that must be accomplished. The application requires accurate position and orientation tracking in order to register virtual elements in the real world using marker-based method. 
Therefore, the system requires a webcam for capturing the real world. The captured image recognizes virtual objects on the visible markers.

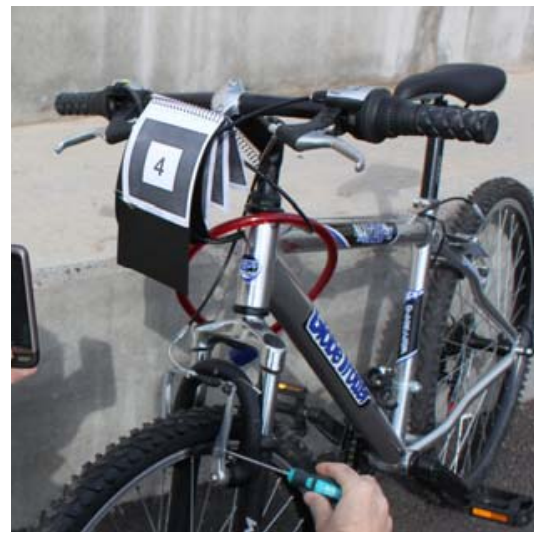

Fig. 1. AR-manual over the bike handlebar.

Program used for development of computer scenes has been Build_AR [17] meanwhile for creation of mobile devices scenes chosen software was AndAR [18], which are both GNU software - General Public license. 3D modeling of the parts manipulated during tasks was performed using Autodesk Inventor 3D software. Besides, textual information about tools is included in every step. 3D graphics are animated so user can understand gestures that should be carried out.

User provided with a mobile phone including camera will lean the augmented book over the bike's handlebar where an included adapter should be set. Through the phone's screen he can see virtual parts superimposed over the real ones (displaced respecting marker). See Fig 1. Besides seeing animated components on the real environment, user will also be able to listen to a recorded voice which will guide him through every task following instructions accordingly.

Most accessible and common device suggested is mobile phone although an AR glasses with earphones included could also be used (Fig.2). Traditional user manual will be substituted by several markers and AR application would be available for download from the product's website.

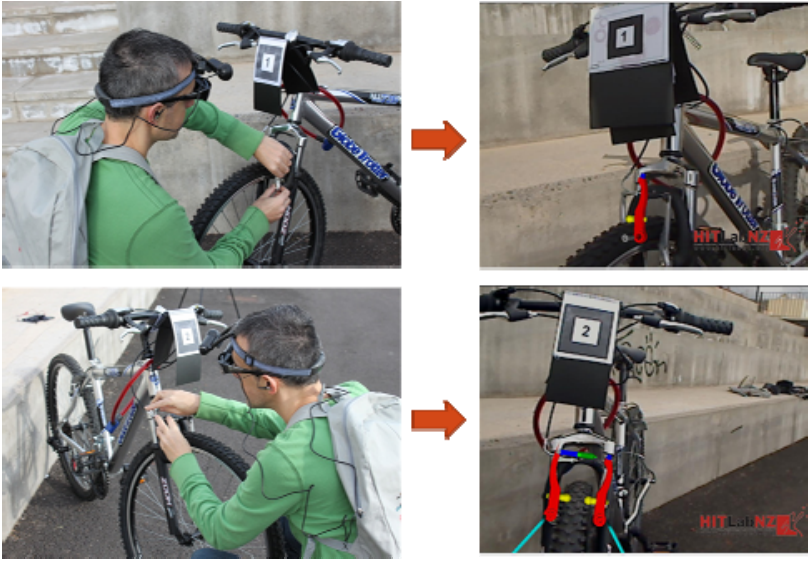

Fig. 2 V-Brakes installation through computer and HMD platform.
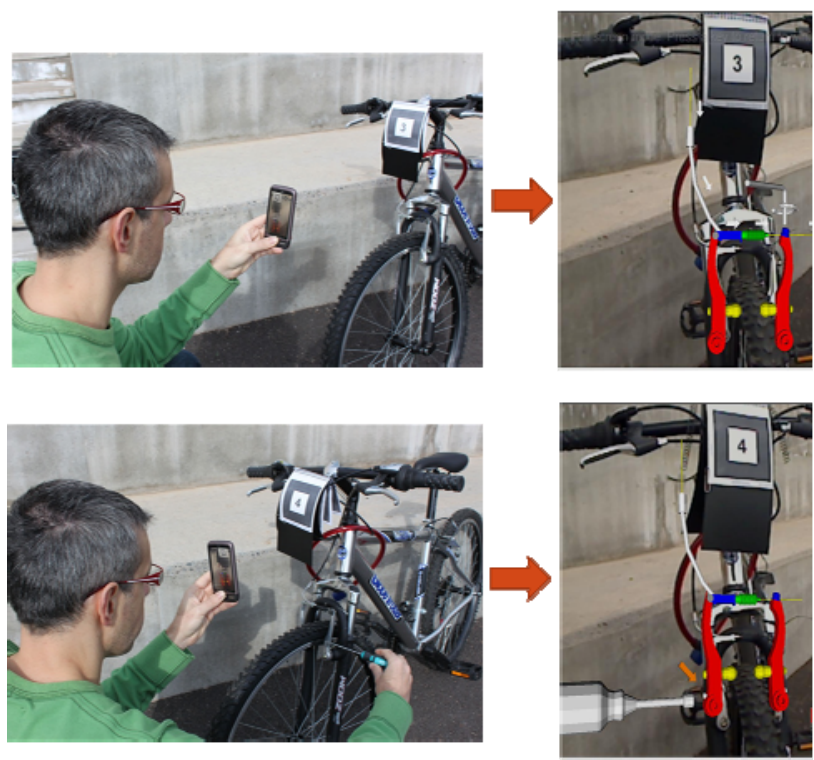

Fig. 3 V-Brakes installation through smartphone platform.

This project is a pilot study which may be extensible to all electronic devices, vehicles, home appliances, etc as they are all provided of user manuals for configuration or installation and usually understanding their instructions becomes a tough task. The possibility of creating those manuals in augmented reality as assistance during training, configuration and installation of those equipment could make learning how to use them much easier.

\section{USABILITY STUDY}

A usability study is intended for finding out the efficacy and efficiency as well as user's satisfaction about use of 
augmented manuals in both platforms (Smartphone and HMD with PC).

According to Bevan [19] any usability study must have these three components, and at least eight or ten participants are needed for making reliable estimations of the results. By the way measures of usability are far more reliable when psychometrically validated questionnaires are used. However, it is difficult getting questionnaires of this kind suitable for being adapted to specific experiences. In this study, survey was made with specific questions for our experience, based on Hornbæk’s [20].

\section{Participants, Design and Procedures}

Measures have been taken from two groups of 8 people each with ages ranging from 18 to 21 years old. There are four men and four women in each group so V-brakes installation is proposed following four steps. Brakes adjustment is not performed in this study. Before the experience one brief meeting was attended by participants. Session one included a brief verbal summary of the purpose and procedures as well as distribution of a consent form and demographic survey. After completion of the survey, participants were summoned on different times and days for carrying out the experiment. Besides MRT and DAT tests were supplied [6] for finding out their spatial abilities levels as different levels of them may have an influence in efficiency and efficacy.

A single hour timeframe was given to each participant for performing the mounting tasks and answering the usability study. Experiment was carried out during two days, first day 8 participants of group 1 used the smartphone while during second day, group 2 participants used an HMD connected to a laptop in their backpacks. At the start, participants of group 1 were given the V-brakes mechanism that should be installed; markers were be set upon the handlebar and access to the website where augmented scenes are downloadable. Finally, they receive explanations about the smartphone used for visualizing scenes. Participants who use the HMD does not need downloading any scenes from the web and they doesn't need knowing application use either. While participant takes the test, observer took timing for each step writing down any issues or comments user may have.

\section{Data Collection and results}

Usability study has three blocks for measuring satisfaction and effectiveness. Participants will assign values for each item according to Likert's scale. Application will be efficient (effectiveness) if it accomplishes the aim it was created for being also trouble free. Its value ranges from one until five in Likert's scale (1= Totally Disagree, $2=$ Disagree, 3= Neither Agree nor disagree, 4= Agree, 5= Totally Agree). Satisfaction will provide user's degree of approval for the product using a five points Likert's scale (1=very bad, 2=bad, 3=not applicable, 4=good, 5=very good). Last block is also dedicated to satisfaction valued using a ten points scale.

Table 1. Survey and usability study results

\begin{tabular}{|c|c|c|}
\hline \multirow{2}{*}{ EFFECTIVENESS (Five values Likert's Scale) } & \multicolumn{2}{|c|}{ Average } \\
\hline & G-1 & G-2 \\
\hline $\begin{array}{l}\text { Proposed steps are appropriate for performing } \\
\text { installation }\end{array}$ & 5.0 & 5.0 \\
\hline I have been able to perform very step & 4.9 & 5.0 \\
\hline $\begin{array}{l}\text { I consider 3D graphics are suitable and similar to } \\
\text { real ones }\end{array}$ & 5.0 & 5.0 \\
\hline Appropriate suggested mounting procedure & 4.6 & 5.0 \\
\hline $\begin{array}{l}\text { I would like having this kind of material available } \\
\text { for other tasks such as video or TV setup as well as } \\
\text { other home appliances }\end{array}$ & 5.0 & 4.8 \\
\hline $\begin{array}{l}\text { I would rather prefer AR manual instead of written } \\
\text { ones. }\end{array}$ & 5.0 & 5.0 \\
\hline \multicolumn{3}{|l|}{ SATISFACTION I (Five values Likert's Scale) } \\
\hline Platform value (Smartphone o HMD) & 4.8 & 3.3 \\
\hline Bike handlebars value & 4.5 & 4.8 \\
\hline $\begin{array}{l}\text { Website downloadable scenes procedures value } \\
\text { (just group 1) }\end{array}$ & 5.0 & - \\
\hline I would recommend these kind of manuals & 5.0 & 5.0 \\
\hline General experience satisfaction? & 5.0 & 4.8 \\
\hline \multicolumn{3}{|l|}{$\begin{array}{l}\text { SATISFACTION II. AR technology applied to } \\
\text { AR manuals (Ten values Likert's Scale) }\end{array}$} \\
\hline Terrible-wonderful & 8.0 & 7.9 \\
\hline Difficult-Easy & 8.8 & 8.6 \\
\hline Frustrating -Satisfying & 8.4 & 8.5 \\
\hline Uninteresting - Very interesting & 8.0 & 9.0 \\
\hline Dull - stimulating & 7.8 & 8.6 \\
\hline Use: Very difficult - Very easy & 8.5 & 9.0 \\
\hline Intuitive system: Not at all - Very much & 8.9 & 9.0 \\
\hline
\end{tabular}

Efficiency will be regarded as speed which user is able to perform a task which is important regarding output. 
Average time spent by each group in V-Brakes installation can be seen on figure 4 .

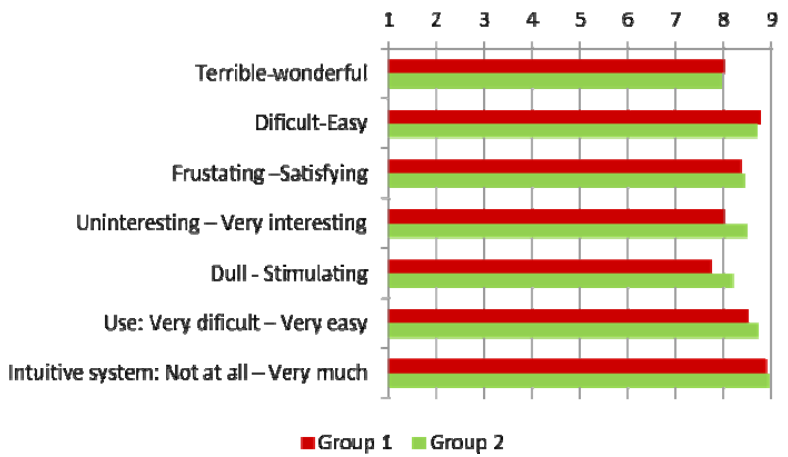

Fig. 4 Satisfaction.

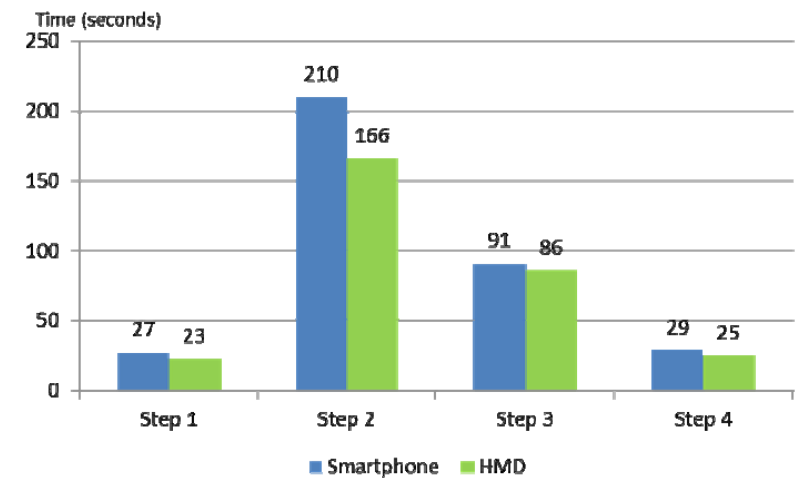

Fig. 5 Performance times.

Results of spatial visualization tests don't require a statistical analysis because it's visually observed that there is no significant difference between groups nor gender.

Table 2. Spatial ability test results

\begin{tabular}{|c|c|c|c|}
\cline { 3 - 4 } \multicolumn{2}{c|}{} & MRT & DAT \\
\hline \multirow{2}{*}{ Group 1 } & Men & $18.75(1.7)$ & $37.25(0.95)$ \\
\cline { 2 - 4 } & Women & $18.25(0.5)$ & $36.25(0.95)$ \\
\hline \multirow{2}{*}{ Group 2 } & Men & $18.75(1.25)$ & $36.25(1.25)$ \\
\cline { 2 - 4 } & Women & $18.5(1.73)$ & $36(0.81)$ \\
\hline
\end{tabular}

Staring from the fact that every participant in the experiment has the same level of spatial ability and no one has experience in installation of this kind of devices it can be stated from results that application is efficient. Observer didn't spot any issue during use of applications in any participant. Results show that proposed method is suitable for installation as all participants were able to complete it.

Everyone regards application as intuitive, stimulating and wonderful. Time ranges obtained from each one of the groups doesn't show any significant difference between installation steps.
In this study we doesn't have a control group because aim is not comparing times spent between using AR application or traditional manual but measuring usability.

\section{CONCLUSION}

AR applications allow user visualizing information for performing tasks in a more comfortable and easier way.

The sort of interface introduced in this work has proved being useful and efficient. Participants feel quite satisfied using this kind of applications for performing manual tasks AR applications on smartphones are very appropriate for support in leisure or domestic tasks. However AR apps using a HMD connected to a laptop are more suitable for working environments such as workshops or labs.

This kind of apps use can be extended for setup and installation of electrical appliances (TV recorder and programmer, Hi-fi systems, home cinemas, game consoles, etc). We propose substitution of the usual user manual for setup and maintenance of home appliances or devices for AR based portable applications. User may access product's website from his mobile device (iPhone, smartphone) for download and installation of the AR application.

\section{REFERENCES}

[1] Schwald, B., Laval, B., “An augmented reality system for training and assistance to maintenance in the industrial context”, Journal of WSCG, Vol. 3(7), pp. 425-432, 2003.

[2] Pentenrieder, K., Bade, C., Doil, F., \& Meier, P., “Augmented Reality-Based Factory Planning - an Application Tailored to Industrial Needs”, Proceeding of the 2007 6th IEEE and ACM International Symposium on Mixed and Augmented Reality, pp. 1-9. Nara, Japón. 2007.

[3] Alt, T., Edelmann, M., et al, “Augmented Reality for Industrial Applications - A New Approach to Increase Productivity", Proceedings of the $6^{\text {th }}$ International Scientific Conference on Work With Display Units, pp. 380-381. Berchtesgaden, Germany. 2002. 
[4] Fischer, J., Eichler, M., Bartz, D., \& Straer, W., “A hybrid tracking method for surgical augmented reality”, Computer \& Graphics, Vol. 31 (1), pp. 39-52, 2007.

[5] Mischkowski, R., Zinser, M., Kubler, A., Krug, B., Seifert, U., \& Zoller, J., “Application of an augmented reality tool for maxillary positioning in orthognathic surgery- A feasibility study”, Journal of CranioMaxillofacial Surgery,Vol. 34 (8), pp. 478-483, 2006.

[6] Martín-Gutiérrez, J., Saorín, JL., Contero, M., Alcañiz, M., Pérez-Lopez, DC., Ortega, M., “Design and Validation of an Augmented Reality for Spatial Abilities Development in Engineering Students”, Computer \& Graphics, Vol. 34(1), pp. 77-91, 2010.

[7] Caudell, T. P., Mizell, D. W., “Augmented reality: An application of head-ups display technology to manual manufacturing processes”, Proceedings of Hawaii International Conference on System Sciences, Vol. II, pp 659-669, 1992.

[8] Rahardja, S., Wu, E., Thalmann, D., Huang, Z., "Visualization of intelligent maintenance systems through mixed reality", Proceeding of the $7^{\text {th }}$ International Conference on Virtual Reality Continuum and its Applications in Industry, VRCAI'08, 2008.

[9] Haritos, T., Macchiarella, N. D. “Augmented Reality (AR) for Aircraft Maintenance Technician's Training”, Proceedings of Society of Applied Learning Technologies: New Technologie, 2007.

[10] Macchiarella, N. D., “Augmenting Reality as a Medium for Job Task Training”, Journal of Instruction Delivery Systems, Vol. 19 (1), pp. 21-24, 2005.

[11] Mizell, D., “Augmented Reality Applications in Aerospace” Proceedings of ISAR '01 - The Second IEEE and ACM International Symposium on Augmented Reality, New York, NY, 2001.

[12] Schwald, B., Figue, J., Chauvineau, E., and et al., "Starmate: Using augmented reality technology for computer guided maintenance of complex mechanical elements”, eBusiness and eWork Conference (e2001), pp.196-202, 2001.

[13] Klinker, G., Creighton, O.,et al., “Augmented maintenance of power plants: A prototyping case study of a mobile AR system”, Proceedings of ISAR '01 - The Second IEEE and ACM International Symposium on Augmented Reality, New York, NY, 2001.

[14] Henderson, S., Feiner, S., Augmented Reality for Maintenance and Repair (ARMAR). Technical Report AFRL-RH-WP-TR-2007-0112, United States Air Force Research Lab.

[15] Henderson, S., Feiner, S., "Evaluating the Benefits of Augmented Reality Documentation for Maintenance and Repair”, IEEE Transactions on Visualization and Computer Graphics, TVCG'11, Vol. 1, 2011.

[16] Benbelkacem, S., Zenati-Henda, N., Belhocine, M., Bellarbi, A., Tadjine, M., “Augmented Reality Platform for Solar Systems Maintenance Assistance”, Proceeding International Symposium on Environment Friendly Energies in Electrical Applications (EFEEA’10), Ghardaïa, Algeria, 2010.

[17] Build_AR. Human Interface Technology Laboratory New Zealand (HIT Lab NZ), http://www.buildar.co.nz/ (2010.03.07)

[18] AndAR project. Android Augmented Reality, http://code.google.com/p/andar/ (2010.03.07)

[19] Bevan, N., "Practical Issues in Usability Measurement”, Interactions, Vol. 13 (6), pp. 42-43, 2006. [20] Hornbæk, K., "Current Practice in Measuring Usability: Challenges to Usability Studies and Research”, International Journal of Human-Computer Studies, Vol.64, pp. 79-102, 2006. 